\title{
Laser Microdissection for Rapid Separation of Spermatozoa or Male Epithelial Cells from Cell Mixtures from Sexual Assault Evidence, and Other Applications for Forensic Analysis
}

Andrew K. Lee

Leica Microsystems, Inc. 2345 Waukegan Road, Bannockburn, IL 60015 USA

The latest laser microdissection technology rapidly and precisely separates specific cell types from mixtures of sexual assault evidence for DNA analysis. Laser microdissection can also be used in other applications of specific cell isolation for analysis. Laser microdissection, originally developed for specific cell microdissection for genomic analysis in cancer research, is a proven technology for capturing individual or groups of cells for DNA, RNA, and protein analysis [1].

The Leica LMD6000 is the latest technology in laser microdissection, which offers forensic scientists an easy and economical system for quickly separating different cell types from a mixture. Based on an automated upright compound microscope, the Leica LMD6000 is a complete turnkey laser microdissection workstation where the user simply circumscribes the cells of interest on a computer monitor and with the click of a button, cells are quickly isolated and collected into PCR tube caps via a unique contact-free, contamination-free method.

Spermatozoa, male epithelial, or female epithelial cells can be rapidly and precisely separated from cell mixtures by laser microdissection for subsequent forensic DNA analysis such as PCR and STR [2-4]. Using specific chromatic stains, immunofluorescence, or FISH, the laser microdissection process quickly collects a few or hundreds of spermatozoa or epithelial cells, thereby significantly decreasing the time associated with current protocols.

Other emerging specific cell capture applications by laser microdissection being investigated by forensic criminalists include analysis of epithelial cell transfer, precise single hair follicle isolation, and parentage analysis from minute amounts of fetal tissue [5-7].

\section{References}

[1] M. Emmert-Buck et al. Science, 274, 5289, 998 (1996)

[2] C.T. Sanders et al., American Academy of Forensic Sciences, Proceedings, 10, 36 (2004).

[3] K.B. Langley et al. $16^{\text {th }}$ International Symposium on Human Identification, Grapevine, TX, “Application of Leica AS Laser Microsystem to expedite forensic sexual assault cases" (Presentation) (2005)

[4] J. Valentine, DNA Scientific Meeting 2006, Shreveport, LA, "Separation of Diploid Cell Using Fluorescence In Situ Hybridization and Laser Microdissection in the Analysis of Sexual Assault Evidence" (Presentation), (2006). 
[5] C. Rubino et al., Journal of Forensic Science, 51, 90 (2006).

[6] D. Di Martino et al. Forensic Sci Int, 146 Suppl, S151-3 (2004)

[7\} D. DiMartino et al. Forensic Sci Int. 146 Suppl, S155-7 (2004) 